\title{
EFEKTIVITAS PENERAPAN AMDAL DALAM PENGELOLAAN LINGKUNGAN HIDUP PADA PEMBANGKIT LISTRIK DI BALI - STUDI KASUS PLTD/G PESANGGARAN
}

\author{
Helga Margareta Hunter ${ }^{1^{*}}$, Made Sudiana Mahendra ${ }^{2)}$, I.G.B. Sila Dharma ${ }^{3)}$ \\ 1)PT General Energy Bali, Bali, Indonesia \\ 2) Fakultas Pertanian Universitas Udayana \\ 3) Fakultas Kelautan dan Perikanan Universitas Udayana \\ *Email: hunterhelga@yahoo.com
}

\begin{abstract}
The development and sustainability of power plant's activity has a positive impact, such as the increased electricity energy which will indirectly boost the economy, but it also has negative impact, such as the rising pressure towards environment. One way to prevent it from damaging environment is to require stakeholders and industry actors to have the environment permit including EIA (Environment Impact Assessment). The objective of this study was to find out the effectiveness of EIA application on power plant on PLTD/G Pesanggaran. This study was conducted with a descriptive qualitative approach which used data from observations, interviews, questionnaires, and literatures. Location of this study was at PLT/D Pesanggaran. The data that were gathered is used to be the base for value determination from valuation categories, so that the value of effectiveness of EIA application in PLTD/G Pesanggaran is subsequently gained. The EIA implementation of PLTD/G Pesanggaran as a whole was sufficient and in accordance with the environmental document. Supervision of RKL-RPL implementation which was done by BLH had been carried out systematically and effectively. The effectiveness value of EIA implementation in PLTD/G Pesanggaran was $94 \%$, which means that the EIA implementation was effective.
\end{abstract}

Keywords: EIA; power plant; effectiveness; management; supervision; environment

\section{PENDAHULUAN}

Kebutuhan energi listrik pada era globalisasi menjadi kebutuhan pokok di seluruh dunia, termasuk Indonesia. Dengan meningkatnya tingkat kesejahteraan masyarakat, maka kebutuhan akan energi listrik juga akan meningkat.

Seiring dengan semakin pesatnya perkembangan industri pariwisata dan tata kota, kebutuhan energi listrik di Bali meningkat dengan pesat. Direktur Bisnis Regional Jawa Bagian Timur dan Bali Amin Subekti mengatakan (2016), kebutuhan energi listrik di Bali dari tahun ke tahun semakin meningkat dan sekarang ini ketersediaan listrik di daerah ini hanya 1.300 megawatt (MW) dengan beban puncak $834 \mathrm{MW}$, sedangkan menurut RUPTL PLN 2016-2025 (2016), kebutuhan energi listrik di Indonesia akan meningkat $8,2 \%$ per tahun dan di Bali sendiri akan meningkat sebesar 7,7\% per tahun. Pemadaman listrik yang sering terjadi setahun belakangan ini di Bali akibat rusaknya kabel transmisi listrik bawah laut yang memasok kebutuhan listrik di Pulau Bali dari Jawa menunjukan adanya ketergantungan pemasokan energi listrik di Bali dari Jawa. Pembangunan beberapa pembangkit listrik (power plant) di Bali dilakukan untuk mengurangi ketergantungan akan energi litrik yang disuplai dari Jawa.
Pembangunan dan keberlangsungan kegiatan power plant memberikan dampak positif yaitu bertambahnya pengadaan energi listrik yang secara tidak langsung meningkatkan perekonomian, namun juga memberikan dampak negatif berupa meningkatnya tekanan terhadap lingkungan. Tekanan terhadap lingkungan dari pembangunan yang kurang memperhatikan daya dukung dan daya tampung lingkungan setempat, pada akhirnya akan menyebabkan kerusakan lingkungan (Wahyono, dkk, 2012). Kerusakan lingkungan tersebut menjadi tanggung jawab bersama seluruh pemangku kepentingan, termasuk masyarakat, pemerintah dan pemrakarsa.

Sari, dkk, (2012) mengungkapkan bahwa salah satu upaya preventif yang dilakukan untuk menghindari kerusakan lingkungan tersebut adalah dengan mewajibkan kepada setiap pelaku industri untuk memiliki Izin Lingkungan dengan menyertakan Analisis mengenai Dampak Lingkungan (Amdal), Upaya Pengelolaan Lingkungan Hidup dan Upaya Pemantauan Lingkungan Hidup (UKL-UPL). Kedua studi tersebut merupakan studi kelayakan lingkungan yang harus dibuat oleh pemrakarasa kegiatan dan atau usaha yang baru atau belum beroperasi, sehingga melalui dokumen ini dapat diperkirakan dampak yang akan timbul dari suatu kegiatan kemudian bagaimana dampak tersebut 
dikelola baik dampak negatif maupun dampak positif.

Pasal 22 ayat (1) UUPLH menyebutkan bahwa "setiap usaha dan/atau kegiatan yang berdampak penting terhadap lingkungan hidup wajib memiliki Amdal" dan Pasal 34 ayat (1) bahwa "setiap usaha dan/atau kegiatan yang tidak termasuk dalam kriteria wajib Amdal, wajib memiliki dokumen UKLUPL". Dokumen lingkungan ini digunakan sebagai instrumen pencegahan pencemaran yang dibuat pada tahap perencanaan usaha dan/atau kegiatan.

Dokumen Amdal memuat Dokumen Kerangka Acuan Analisis Dampak Lingkungan (KA-Andal), Dokumen Analisis Dampak Lingkungan Hidup (ANDAL), Dokumen RencanaPengelolaan Lingkungan Hidup (RKL), dan Dokumen Rencana Pemantauan Lingkungan Hidup (RPL). Pasal 2 ayat (1) Peraturan Pemerintah Republik Indonesia nomor 27 tahun 2012 tentang Izin Lingkungan menetapkan setiap usaha dan/atau kegiatan yang wajib memiliki Amdal atau UKL-UPL wajib memiliki Izin Lingkungan. Pasal 53 ayat (1) huruf b mengatakan setiap pemegang izin lingkungan memiliki kewajiban membuat dan menyampaikan laporan pelaksanaan terhadap persyaratan dan kewajiban dalam izin lingkungan kepada Menteri, gubernur, atau bupati/ walikota dan sesuai Pasal 53 ayat (2) laporan tersebut disampaikan secara berkala setiap 6 (enam) bulan.

Menurut Sabaruddin (2007), instansi yang bertanggung jawab di bidang lingkungan hidup mempunyai kewenangan dalam pengendalian dampak lingkungan, pencemaran, dan kerusakan lingkungan serta pengawasan pelaksanaan UKLUPL di daerahnya. Peran yang efektif dari pemerintah diperlukan dalam dokumen lingkungan, agar dapat lebih meningkatkan kualitas dan integritas dokumen lingkungan (Ross, et. al., 2006). Koordinasi/hubungan dan mekanisme kerja antar pusat, provinsi, dan kabupaten/kota sangat diperlukan, sehingga terdapat kejelasan mandat, untuk menghindarkan terjadinya kerancuan dan tumpang tindihnya wewenang dan tanggung jawab di bidang pengelolaan sumberdaya alam dan lingkungan. Sosialisasi dan komunikasi menjadi kunci penting bagi implementasi pembangunan berwawasan lingkungan (Sarbi, 2006).

Pada kenyataannya, studi kelayakan lingkungan baik dalam bentuk Amdal maupun UKL-UPL yang dijadikan usaha preventif tidak selalu berjalan dan berhasil optimal. Menurut Rosita dalam Sambutan Rapat Kerja Amdal tahun 2009 (Wahyono, dkk, 2012), sampai saat ini masih banyak dokumen Amdal yang berkualitas buruk, masih tingginya tingkat plagiasi diantara dokumen Amdal, dan sebagainya. Dilaporkan bahwa ada sekitar 9.000 lebih dokumen Amdal telah disetujui oleh pemerintah, namun tidak menjamin kerusakan lingkungan dapat diminimalkan. Penyebabnya antara lain komisi
Amdal belum semua berfungsi dengan baik dan lemahnya penegakan hukum lingkungan.

Revitalisasi sistem Amdal dilakukan oleh pemerintah pada tahun 2004 karena dirasakan terdapat banyak hal yang kurang dalam pelaksanaan Amdal. Hal ini diperkuat dengan masukan beberapa pakar Amdal. Ada beberapa alasan mengapa program revitalisasi dilakukan, antara lain (Wahyono, dkk, 2012):

a. Efektivitas Amdal perlu ditingkatkan karena Amdal belum dilakukan sebagai perangkat pencegahan dampak lingkungan dan cenderung hanya untuk memenuhi persyaratan administrasi saja.

b. Kualitas Amdal masih sangat rendah. Hasil evaluasi pada tahun 2004 menunjukan hanya $22 \%$ dari sampel Amdal yang dievaluasi memiliki katagori baik dan sangat baik.

c. Pelaksanaan Amdal belum dilakukan dengan serius dan konsisten.

d. Penaatan dan penegakan hukum Amdal belum efektif atau persisnya tidak ada upaya pentaatan hukum.

Menurut Wahyono, dkk. (2012), efektivitas pelaksanaan Amdal juga perlu ditingkatkan karena beberapa fakta menunjukan bahwa pada kenyataannya:

a. Pemrakarsa baru menyusun Amdal setelah izin mulainya kegiatan dikeluarkan, artinya Amdal tidak berperan sebagai alat pembantu pengambilan keputusan.

b. Pemrakarsa masih memandang Amdal sebagai tambahan biaya ketimbang alat pengelolaan lingkungan hidup. Pengelolaan lingkungan yang terdapat dalam RKL-RPL belum berorientasi pada langkah-langkah untuk penurunan biaya produksi.

c. Perencanaan Amdal sebagai bahan studi kelayakan masih lemah karena sering kali terlambat dilaksanakan setelah aspek ekonomi dan teknis dinyatakan layak. Dengan demikian rendah sekali kemungkinan bagi hasil studi Amdal untuk memberikan masukan perbaikan dan masukan alternatif bagi kegiatan.

d. Amdal disusun dengan kualitas rendah dan cenderung tidak fokus.

e. Penilai Amdal belum mampu mengarahkan agar kualitas Amdal dapat ditingkatkan, masih banyak dokumen yang berkualitas rendah diloloskan juga dengan berbagai alasan.

Oleh karena itu, penelitian ini dilakukan untuk mengetahui tentang efektivitas penerapan Amdal dalam Pengelolaan Lingkungan Hidup pada pembangkit listrik di Bali - Studi Kasus PLTD/G Pesanggaran. 


\section{METODOLOGI}

\subsection{Lokasi dan Waktu Penelitian}

Penelitian ini dilakukan di PLTD/G Pesanggaran di Kota Denpasar, Bali. Alasan pemilihan lokasi penelitian ini adalah pembangkit listrik tersebut telah memiliki dokumen Amdal. Penelitian dilaksanakan selama 6 bulan, mulai dari Bulan Juli sampai dengan Desember 2016.

\subsection{Prosedur Penelitian}

Sesuai dengan bentuk pendekatan penelitian kualitatif dan sumber data yang akan digunakan, maka teknik pengumpulan data yang digunakan adalah dengan teknik observasi, wawancara, kuesioner, dan studi pustaka.

\subsection{Analisis Data}

Data primer yang terkumpul melalui kuesioner dan wawancara dilakukan pengolahan dengan menggunakan analisis deskriptif kualitatif. Data berupa deskripsi, interpretasi maupun nilai kualitatif akan dikelompokan tersendiri sebagai data pendukung dalam penyusunan laporan.

Efektivitas adalah suatu keadaan yang menunjukkan tingkat keberhasilan atau kegagalan kegiatan dalam mencapai tujuan yang telah ditetapkan terlebih dahulu. Dalam efektivitas penerapan Amdal dan pelaksanaan RKL-RPL dalam pengelolaan lingkungan hidup di Bali, Kriteria efektivitas pengelolaan lingkungan yang dipakai adalah (Wahyono, 2012):

$$
\begin{array}{cc}
0-33 \% & \text { : belum efektif } \\
34-66 \% & \text { : cukup efektif } \\
67-100 \% & \text { : sudah efektif }
\end{array}
$$

Hasil analisis data sesuai dengan permasalahan dan tujuan penelitian disajikan dalam bentuk formal dan informal. Dalam bentuk informal, yakni berupa uraian kalimat secara deskriptif yang menjelaskan semua aktivitas penelitian yang disusun secara sistematis dalam bentuk bab-bab. Selanjutnya, dalam bentuk formal, yakni dapat berupa tabel, yaitu pendeskripsian tentang data hasil penelitian, baik berupa angka maupun kata-kata; berupa gambar, yaitu visualisasi yang melukiskan segala sesuatu yang berkaitan dengan penelitian.

\section{HASIL DAN PEMBAHASAN}

\subsection{Deskripsi Kegiatan Perusahaan}

PT. Indonesia Power UP Bali adalah sebuah perusahaan yang bergerak di bidang Pembangkit Tenaga Listrik. yang terletak di Jalan Brigjen I Gusti Ngurah Rai nomor 535, Kelurahan Pedungan, Kecamatan Denpasar Selatan, Kota Denpasar, Provinsi Bali. Dokumen Amdal yang dimiliki sesuai dengan SK Amdal yang disetujui No. 371 Tahun 2004 tanggal 25 November 2004 dan adendum surat persetujuan Kelayakan Lingkungan dari Gubernur Bali nomor 660.1/1748/BLH/2015 tanggal 14 Agustus 2015. Luas lahan yang dimiliki lebih kurang 71.970 $\mathrm{m}^{2}(7,2 \mathrm{Ha})$ dan di atas lahan tersebut berdiri bangunan gedung kantor, tangki induk BBM, tempat parkir, taman, mesin PLTD/G 12 unit, Pembangkit Listrik Tenaga Gas (PLTG) sebanyak 4 unit dan 1 diantaranya menggunakan pemantauan Continous Emission Monitoring System (CEMS). Kapasitas terpasang pada PLTG 125,45 MW dan PLTD/G 200 MW yang bisa menggunakan dua metode bahan bakar yaitu Bahan Bakar Minyak (BBM) dan Bahan Bakar Gas (BBG).

Mesin-mesin pembangkit tersebut telah dioperasikan sejak tahun 1974 sampai dengan sekarang dan didukung oleh 165 personil yang terdiri dari 1 orang General Manager, 5 Manajer Bidang dan 180 orang staf.

\subsection{Pelaksanaan Pengelolaan dan Pemantauan}

PLTD/G Pesanggaran dalam melakukan kegiatan pembangkit listrik menimbulkan dampak terhadap lingkungan, sehingga memerlukan upaya pengelolaan dan pemantauan lingkungan dan pelaksanaannya dilakukan oleh perusahaan sebagaimana tertuang dalam dokumen RKL-RPL. Semua komponen lingkungan, baik komponen geofisik kimia, biologi, sosial ekonomi, sosial budaya dan kesehatan masyarakat, telah dilakukan upaya pengelolaan, namun untuk pemantauan lingkungan ada beberapa parameter yang belum dipantau. Pelaksana pengelolaan dan pemantauan lingkungan pada PLTD/G Pesanggaran dilakukan seluruhnya oleh perusahaan dengan bagian terkait. Pengawasan dari instansi/dinas mendorong pelaksanaan upaya pengelolaan dan pemantauan lingkungan pada PLTD/G Pesanggaran.

Seluruh responden merasakan manfaat pelaksanaan pengelolaan dan pemantauan lingkungan pada PLTD/G Pesanggaran yang dilakukan. Menurut hasil penelitian, manfaat yang didapat pemrakrsa dari pelaksanaan pengelolaan dan pemantauan lingkungan adalah lingkungan tetap bersih dan lingkungan tidak rusak dan tercemar.

Kendala dalam pelaksanaan pengelolaan dan pemantauan lingkungan pada PLTD/G Pesanggaran sebagian besar adalah karena sulitnya sosialisasi ke masyarakat sekitar yang belum memahami kaidah lingkungan. Biaya, ketersediaan sumber daya manusia dan tidak adanya teknologi juga menjadi salah satu kendala pelaksanaan pengelolaan dan pemantauan lingkungan.

PLTD/G Pesanggaran membuat laporan semester pelaksanaan pengelolaan dan pemantauan lingkungan dan melakukan pelaporan setiap semester atau dua kali setiap tahunnya dengan format yang telah memenuhi ketentuan peraturan. 
PLTD/G Pesanggaran juga telah memiliki program Coorporate Social Responsibility (CSR) dan community development (comdev). Program CSR yang dilakukan antara lain penanaman 3500 pohon di sekitar Bali bekerja sama dengan BLH Kota Denpasar, budidaya kuda laut di Pulau Serangan dan pemberian sepeda kepada masyarakat untuk pengembangan Ekowisata Desa Pedungan. Untuk comdev yang dijalankan adalah mengembangkan Koperasi dan Kelompok Usaha Kecil.

\subsection{Pelaksanaan Pengawasan Pengelolaan dan Pemantauan Lingkungan}

Pelaksanaan pengawasan pengelolaan dan pemantauan lingkungan pada PLTD/G Pesanggaran dilakukan oleh instansi pemerintah pada bidang lingkungan dari pemerintah pusat sampai pemerintah daerah. Instansi yang melakukan pengawasan terhadap pengelolaan dan pemantauan lingkungan PLTD/G Pesanggaran adalah BLH Kota Denpasar, BLH Provinsi Bali, dan Pusat Pengendalian Pembangunan Ekoregion (P3E) Bali Nusra (Kementerian Lingkungan Hidup dan Kehutanan Republik Indonesia). Hasil penelitian ini didapat dari penelitian yang dilakukan terhadap BLH Kota Denpasar mengenai pengawasan pengelolaan dan pemantauan lingkungan di PLTD/G Pesanggaran.

Pengawasan BLH Kota Denpasar dimulai dari pembahasan penyusunan dokumen Amdal PLTD/G Pesanggaran. Kegiatan pengawasan penerapan Amdal PLTD/G Pesanggaran dilaksanakan secara sistematis dengan mekanisme sebagai berikut:

a. Melakukan kunjungan lapangan secara rutin dan berkala.

b. Membaca dan mencermati laporan pelaksanaan RKL-RPL.

c. Jika ada penyimpangan dari standar baku mutu, BLH akan memberikan saran kepada PLTD/G Pesanggaran untuk melakukan perbaikan.

d. Melakukan pengawasan secara terus menerus hingga tercapai standar baku mutu yang ditetapkan.

Laporan pelaksanaan RKL-RPL secara rutin setiap semester disampaikan PLTD/G Pesanggaran kepada BLH Kota Denpasar. Dalam pelaksanaan pengawasan yang dilakukan BLH Kota Denpasar, tidak ada penyimpangan yang ditemukan baik dalam pengelolaan dan pemantauan lingkungan yang dilakukan PLTD/G Pesanggaran. Belum pernah ada sanksi administratif yang diberikan BLH Kota Denpasar kepada PLTD/G Pesanggaran.

Sempat ada informasi atau keluhan dari warga sekitar PLTD/G ke BLH secara langsung atau tidak langsung. Informasi atau keluhan tersebut antara lain permasalahan mengenai perluasan lahan dan juga suara bising dari mesin pembangkit, namun permasalahan tersebut telah diselesaikan.
BLH Kota Denpasar sebagai pengawas penerapan Amdal PLTD/G Pesanggaran menilai bahwa pengelolaan dan pemantauan yang dilakukan PLTD/G Pesanggaran sudah sesuai dan efektif.

\subsection{Efektivitas Pelaksanaan Amdal}

Nilai efektivitas penerapan Amdal PLTD/G Pesanggaran didapat dari analisis deskriptif kualitatif dari kategori penilaian efektivitas penerapan Amdal (Wahyono, 2012) seperti terlihat dalam Lampiran 1. Seluruh data yang didapat dari observasi, kuesioner, dan wawancara menjadi dasar penilaian untuk 25 indikator yang dibagi menjadi 8 bagian.

PLTD/G Pesanggaran telah memiliki cerobong yang dilengkapi dengan tangga dan lubang sampling yang memenuhi syarat serta telah menggunakan CEMS, sehingga untuk indikator pertama didapatkan nilai 4. Begitu juga untuk hasil uji laboratorium emisi dan udara ambien dilakukan secara periodik untuk semua parameter dan hasilnya sesuai baku mutu yang ditetapkan, sehingga untuk indikator kedua didapat nilai 4.

Kebisingan tertinggi di PLTD/G Pesanggaran hanya di sekitar mesin pembangkit. Alat peredam sudah dipasang di mesin pembangkit dan areal mesin pembangkit sehingga suara bising mesin tidak keluar. Penggunaan APD dan penanaman pohon juga sudah dilakukan untuk mengurangi suara bising, sehingga untuk indikator ketiga dan keempat mendapat nilai masing-masing 4 .

Indikator selanjutnya yaitu pengendalian pencemaran air juga mendapat angka 4 karena PLTD/G Pesanggaran telah memiliki IPAL yang dilengkapi dengan pengukur debit di inlet dan outlet serta dilakukan uji lab berkala. Pemantauan intern untuk air juga dilakukan dan juga dilakukan pencatatan setiap bulannya sehingga untuk indikator pemantauan intern mendapat nilai 4 .

Uji laboratorium untuk air sumur dilakukan secara periodik, namun hasil uji laboratorium untuk beberapa parameter ada yang melebihi baku mutu seperti paremeter seng pada bulan Juni 2015 mencapai $0,110 \mathrm{mg} / \mathrm{l}$ sedangkan baku mutu yang diperbolehkan hanya $0,05 \mathrm{mg} / \mathrm{l}$ dan parameter sulfida mencapai $0,009 \mathrm{mg} / \mathrm{l}$ sedangkan baku mutu yang diperbolehkan hanya 0,002 mg/l (Laporan RKL-RPL PLTD/G Pesanggaran, 2015). Begitu pula parameter besi pada bulan Juni 2016 mencapai 0,112 mg/l sedangkan baku mutu yang diperbolehkan adalah 0,1 mg/l (Laporan RKL-RPL PLTD/G Pesanggaran, 2016). Hal ini menyebabkan nilai untuk indikator ketujuh mendapat nilai 3 .

Uji laboratorium untuk air kali/sungai dan air laut dilakukan secara periodik, namun hasil uji lab untuk beberapa parameter air sungai melebihi baku mutu seperti parameter amonia dan BOD pada bulan Juni 2015 (Laporan RKL-RPL PLTD/G Pesanggaran, 
2015). Parameter amonia mencapai $2,767 \mathrm{mg} / \mathrm{l}$, sedangkan baku mutu yang ditetapkan adalah 0,5 $\mathrm{mg} / \mathrm{l}$ dan parameter BOD mencapai 32,04 mg/l, sedangkan baku mutu yang ditetapkan adalah 12 $\mathrm{mg} / \mathrm{l}$. Hal ini menyebabkan nilai untuk indikator kedelapan dari kategori penilaian mendapat nilai 3.

Uji laboratorium terhadap biota flora dan fauna air dilakukan secara periodik. Hasil yang ditunjukan mengalami fluktuasi untuk jumlah jenis, jumlah individu, dan indeks diversitas baik fauna maupun flora seperti terlihat pada Tabel 1. Hasil uji laboratorium terakhir (Pemantauan Biologi, 2016) menunjukan peningkatan jumlah jenis, jumlah individu, dan indeks diversitas sehingga untuk indikator kategori penilaian kesembilan mendapat nilai 4.

Pengelolaan dan pemantauan limbah PLTD/G Pesanggaran dilakukan dengan baik. Pengelolaan limbah cair dilakukan dengan IPAL yang dioperasikan secara rutin. Limbah cair juga diuji secara periodikdan hasilnya baik di bawah baku mutu yang ditetapkan. Limbah B3 diletakan di Tempat Penyimpanan Sementara (TPS) Limbah B3 yang telah memiliki ijin, setiap limbah B3 diberi label untuk setiap jenisnya, dan pengolahan limbah B3 akan dilakukan dengan bekerja sama dengan pihak ketiga yang telah memiliki ijin. Pengelolaan limbah sampah/padat dilakukan dimulai dari penyediaan tempat sampah di beberapa titik untuk selanjutnya dibawa ke TPS untuk dipilah. Sampah organik akan dijadikan pupuk dengan metode composting atau bekerja sama dengan pihak ketiga. Sampah anorganik akan dipilah untuk dimanfaatkan oleh pihak ketiga. Berdasarkan deskripsi tersebut, nilai untuk indikator kesepuluh-ketigabelas masingmasing 4 .

Berdasar hasil wawancara, perekrutan tenaga lokal sudah dilakukan oleh perusahaan hanya sekitar 15-20\% dan mayoritas oleh perusahaan outsource. Tenaga kerja lainnya berasal dari luar Bali karena perekrutan dilakukan dari pusat. Perekrutan tenaga lokal masih berada dibawah $25 \%$ sehingga untuk indikator keempatbelas diberi nilai 1. Pendapatan yang diberikan kepada tenaga kerja di PLTD/G sesuai dengan upah minimum regional (UMR). Para pekerja juga diberikan asuransi serta tunjangan lainnya seperti tunjangan hari raya dan tunjangan jabatan, sehingga untuk indikator kelima belas diberikan nilai 4 .

Keberadaan usaha kecil menengah (UKM) di sekitar PLTD/G seperti beberapa warung makan dan warung yang menjual barang kebutuhan sehari-hari menunjukan adanya peningkatan kesempatan berusaha. Meski tidak banyak, tetapi UKM tersebut tertata rapih. Indikator keenam belas tentang peningkatan kesempatan berusaha diberi nilai 3 . Untuk program CSR, perusahaan telah memiliki kebijakan dan secara rutin dilaksanakan sehingga indikator ketujuh belas diberi nilai 4 .

Pengelolaan gangguan K3 dilakukan dengan menyediakan APD dan mewajibkan para pekerja untuk mengenakan APD sesuai dengan SOP masingmasing bagian, sehingga untuk indikator kedelapan belas diberi nilai 4. Pengelolaan lalu lintas di sekitar PLTD/G Pesanggaran dilakukan dengan pengadaan lahan parkir, rambu lalu lintas, dan petugas keamanan, sehingga nilai untuk indikator kesembilan belas adalah 4 .

Manajemen PLTD/G Pesanggaran memberikan wewenang kepada divisi K3 Lingkungan (K3L) untuk bertanggung jawab terhadap penerapan Amdal dan pelaksanaan RKL-RPL. Divisi K3L akan melakukan sosialisasi dengan divisi lain dan melakukan koordinasi untuk pelaksanaan pengelolaan dan pemantauan lingkungan dengan divisi yang berkaitan. Karena pelaksanaan pengelolaan dan pemantauan dilakukan secara periodik dan terintegrasi maka manfaat dari pelaksanaan pengelolaan dan pemantauan agar lingkungan tidak tercemar dan rusak menjadi efisien dan mencapai 75-100\%. Berdasarkan deskripsi tersebut, nilai untuk indikator kedua puluh dan dua puluh satu adalah masing-masing 4.

PLTD/G Pesanggaran secara rutin melaporkan kegiatan pengelolaan dan pemantauan kepada BLH Kota Denpasar dan BLH Provinsi Bali. Laporan yang dikumpulkan antara lain Laporan Pelaksanaan RKLRPL yang dilakukan setiap semester, Laporan Pemantauan Biologi yang dilakukan setiap 3 bulan, dan Laporan pengelolaan limbah B3. Pelaksanaan pengelolaan dan pemantauan serta pelaporan dilakukan secara rutin sehingga menciptakan lingkungan yang baik sehingga tidak ada sanksi adimistratif dari pemerintah setempat untuk PLTD/

Tabel 1. Data kuantitatif fauna dan flora air PLTD/G Pesanggaran periode 2015-2016

\begin{tabular}{|c|c|c|c|c|c|c|c|}
\hline \multirow{2}{*}{ No } & \multirow{2}{*}{ Parameter } & \multicolumn{3}{|c|}{ Fauna } & \multicolumn{3}{|c|}{ Flora } \\
\hline & & Juni 2015 & Des 2015 & Mar 2016 & Juni 2015 & Des 2015 & Juni 2016 \\
\hline 1 & Jumlah jenis & 17 & 14 & 15 & 15 & 11 & 13 \\
\hline 2 & Jumlah individu & 134 & 74 & 102 & 635 & 594 & 605 \\
\hline 3 & Indeks diversitas & 2,431 & 2,433 & 2,539 & 1,5421 & 1,5563 & 1,7794 \\
\hline
\end{tabular}

Sumber: Pemantauan Biologi (Fauna Air dan Flora Air) di Lingkungan PLTD/G/U Pesanggaran-Bali (2016) 
G Pesanggaran. Aduan dari masyarakat tentang PLTD/G Pesanggaran juga tidak pernah diterima BLH Kota Denpasar. Kerja sama dengan instansi terkait pengelolaan lingkungan juga dilakukan antara lain kerja sama dengan BLH Kota Denpasar untuk membuat 1000 biopori di sekitar Pesanggaran dan kerja sama dengan PPLH untuk pemantauan biota. Berdasarkan deskripsi tersebut maka nilai untuk indikator kedua puluh dua sampai dua puluh lima masing-masing adalah 4.

Berdasarkan hasil analisa data dengan menggunakan analisis deskriptif kualitatif, efektivitas penerapan Amdal PLTD/G Pesanggaran adalah 94\%. Sesuai kriteria efektifitas pengelolaan lingkungan yang dipakai Wahyono (2012), nilai efektifitas penerapan Amdal PLTD/G Pesanggaran berada dalam kisaran $67-100 \%$ yaitu sudah efektif.

\subsection{Evaluasi Pelaksanaan RKL-RPL PT Indonesia Power UP Bali}

Berdasarkan hasil kajian pelaksanaan pengelolaan dan pemantauan lingkungan yang telah dilaksanakan oleh PLTD/G Pesanggaran terlihat pada Tabel 2.

Dari Tabel 2. dapat diuraikan sebagai berikut:

1) Pengelolaan dampak pada kualitas udara

Pengelolaan dengan melakukan penghijauan, pemasangan CEMS, pemasangan filter di setiap

Tabel 2. Evaluasi Pelaksanaan RKL-RPL PLTD/G Pesanggaran

\begin{tabular}{llll}
\hline \multirow{2}{*}{ No Komponen lingkungan } & \multicolumn{2}{c}{ Pelaksanaan } & \multicolumn{1}{c}{ Ket } \\
\cline { 3 - 3 } & \multicolumn{2}{c}{ Ya Tidak } & \\
\hline 1 & Kualitas udara & $\mathrm{V}$ & Belum sesuai \\
2 & Kebisingan & $\mathrm{V}$ & Hasil sesuai \\
3 & Kualitas air & $\mathrm{V}$ & Hasil belum sesuai \\
4 & Limbah padat & $\mathrm{V}$ & Hasil sesuai \\
5 & Hidrologi & $\mathrm{V}$ & Hasil sesuai \\
6 & Pendapatan masyarakat & $\mathrm{V}$ & Hasil sesuai \\
7 & Kenyamanan hidup & $\mathrm{V}$ & Hasil sesuai \\
8 & Persepsi masyarakat & $\mathrm{V}$ & Hasil sesuai \\
9 & Kesehatan masyarakat & $\mathrm{V}$ & Hasil sesuai \\
10 & Pola lalu lintas & $\mathrm{V}$ & Hasil belum sesuai \\
\hline
\end{tabular}

Sumber: Analisis data (2016) stack, dan pemeliharaan setiap mesin pembangkit dan mesin pendukung. Kualitas udara dan emisi sudah dipantau secara rutin. Pengujian udara ambien sudah dilakukan dengan uji laboratorium dan dilaporkan dalam laporan RKL-RPL, untuk emisi sudah dilakukan menggunakan CEMS namun uji laboratorium emisi belum dilakukan. Kualitas udara ambien dan emisi di PLTD/G Pesanggaran masih berada di bawah baku mutu yang ditetapkan peraturan perundang-undanganan.

2) Pengelolaan dampak pada kebisingan

Pengendalian kebisingan dengan memasang alat peredam suara pada alat dan gedung pembangkit, penggunaan APD, penanaman pohon di sekitar pembangkit, dan pemeliharaan mesin pembangkit. Pengujian terhadap kebisingan sudah dilakukan dan sudah sesuai dengan baku mutu yang ditetapkan peraturan perundangundanganan seperti ditampilkan pada Tabel 3. Hasil uji juga sudah dilaporkan kepada instansi melalui laporan RKL-RPL setiap semester.

3) Pengelolaan kualitas air

Pengelolaan untuk kualitas air dilakukan dengan membuat IPAL, membuat bak penampungan limbah cair, dan pengolahan limbah cair. Pengujian untuk kualitas air dilakukan secara rutin untuk air limbah, air tanah, dan air laut sekitar. Hasil uji laboratorium untuk air sudah dilaporkan kepada instansi melalui laporan RKL-RPL setiap semester. Beberapa hasil uji laboratorium untuk air sumur di Pesanggaran dan air sungai sekitar PLTD/G Pesanggaran melebihi baku mutu yang ditetapkan peraturan perundang-undanganan.

4) Pengelolaan dampak pada limbah padat

Pengelolaan limbah padat dilakukan antara lain dengan menyediakan tempat sampah terpisah, melakukan 3R, menyimpan limbah B3 di tempat penyimpanan yang sudah disediakan dan bekerja sama dengan pihak lain yang memiliki izin untuk pengolahannya, dan melakukan composting untuk limbah padat organik. Laporan pengolahan limbah B3 juga telah dilaksanakan secara rutin.

Tabel 3. Data Pengujian Intensitas Kebisingan PLTD/G Pesanggaran (Juni 2016)

\begin{tabular}{|c|c|c|c|c|}
\hline \multirow{2}{*}{ Lokasi Pengukuran } & \multirow{2}{*}{ Satuan } & \multicolumn{2}{|c|}{ Hasil Pengujian } & \multirow{2}{*}{ Baku Mutu } \\
\hline & & Range & Rerata & \\
\hline Depan Kantor Pertanian (BPTP) & $\mathrm{dB} \cdot \mathrm{A}$ & $54,3-59,2$ & 55,96 & 70 \\
\hline Halaman Parkir & $\mathrm{dB} . \mathrm{A}$ & $58,7-63,3$ & 59,68 & 85 \\
\hline Timur Pembangkit & $\mathrm{dB} . \mathrm{A}$ & $45,9-53,9$ & 48,38 & 70 \\
\hline Barat Pembangkit & $d B . A$ & $58,4-69,1$ & 65,10 & 70 \\
\hline Perkantoran & $\mathrm{dB} . \mathrm{A}$ & $58,4-69,1$ & 65,10 & 70 \\
\hline
\end{tabular}

Sumber: Laporan Pemantauan dan Pengelolaan Lingkungan PLTD/G Pesanggaran (2016) 
5) Penurunan Biota air

Pengelolaan biota air dilakukan antara lain dengan menyediakan waste water treatment dan oil separator, penyediaan TPS limbah B3 untuk oli dan sludge, dan melakukan treatment pada air yang akan dibuang ke media lingkungan. Pemantauan dilakukan dengan melakukan penelitian biologi yang hasilnya dilaporkan secara rutin kepada instansi terkait.

6) Pengelolaan dampak pada sosial ekonomi dan budaya.

Pengelolaan dilakukan antara lain dengan melakukan social mapping, membuat dan menjalankan program CSR dan comdev, dan berpartisipasi dalam kegiatan masyarakat setempat.

7) Pengelolaan dampak kesehatan

Pengelolaan lingkungan dilakukan berkaitan dengan kecelakaan dan gangguan kesehatan antara lain dengan penggunaan APD, penetapan SOP, dan penanaman pohon untuk mengurangi penyebaran polusi serta pelaksanaan jaminan asuransi kesahatan terhadap pekerja dan masyarakat yang terkena dampak.

8) Pelaksanaan pendukung pengelolaan lingkungan lainnya

Selain pelaksanaan pengelolaan lingkungan yang sesuai dengan RKL-RPL, PLTD/G Pesanggaran juga melaksanakan pelaksanaan pengelolaan lingkungan yang didasarkan pada ISO 14001:2004 tentang Sistem Manajemen Lingkungan dan Sistem Manajemen Keselamatan dan Kesehatan Kerja (SMK3). PLTD/G Pesanggaran juga telah ikut dalam Program Penilaian Peringkat Kinerja Perusahaan (PROPER) yang merupakan salah satu upaya Kementerian Negara Lingkungan Hidup untuk mendorong penaatan perusahaan dalam pengelolaan lingkungan hidup melalui instrumen informasi.

\section{SIMPULAN DAN SARAN}

\subsection{Simpulan}

1. Penerapan Amdal oleh PLTD/G Pesanggaran secara keseluruhan sudah cukup sesuai dengan dokumen lingkungan. Beberapa kegiatan pengelolaan dan pemantauan khususnya kualitas limbah, air, dan emisi perlu ditingkatkan termasuk dalam hal pelaporan pelaksanaan pengelolaan dan pemantauan.

2. Pengawasan pelaksanaan RKL-RPL yang dilakukan oleh instansi melalui Badan Lingkungan Hidup dilaksanakan secara sistematis dan sudah efektif.
3. Dari hasil penelitian diketahui bahwa PLTD/G Pesanggaran memiliki nilai efektivitas sebesar 94\% dan berada pada kelompok atas dengan nilai rentang $67-100 \%$ yang menunjukan bahwa pelaksanaan pengelolaan dan pemantauan lingkungan sudah efektif.

\subsection{Saran}

Berdasarkan penelitian yang dilakukan terhadap penerapan Amdal pada PLTD/G Pesanggaran, saran yang dapat diberikan penulis adalah pemrakarsa perlu melakukan kegiatan pengelolaan dan pemantauan lingkungan secara tepat waktu sesuai dengan arahan dokumen RKLRPL, termasuk dalam hal penyampaian pelaporan pelaksanaan pengelolaan dan pemantauan lingkungan, khususnya terkait dengan kualitas limbah, air dan emisi dengan bukti-bukti analisis dan dokumen pendukung lainnya, serta pemrakarsa harus menaati peraturan perundangan sesuai dengan kondisi terkini secara cermat.

\section{DAFTAR PUSTAKA}

Menteri Energi dan Sumber Daya Mineral Republik Indonesia. 2016. Keputusan Menteri Energi dan Sumber Daya Mineral Republik Indonesia Nomor 5899K/20/MEM/2016 tentang Pengesahan Rencana Usaha Penyediaan Tenaga Listik PT Perusahaan Listrik Negara (persero) Tahun 2016 s.d. 20255. Indonesia.

Pemerintah Republik Indonesia. 2009. Undangundang Republik Indonesia Nomor 32 Tahun 2009 tentang Perlindungan dan Pengelolaan Lingkungan Hidup. Lembaran Negara RI Tahun 2009, No. 140. Sekretariat Negara, Indonesia.

Pemerintah Republik Indonesia. 2012. Peraturan Pemerintah Republik Indonesia Nomor 27 Tahun 2012 tentang Izin Lingkungan. Lembaran Negara RI Tahun 2012, No. 48. Sekretariat Negara, Indonesia.

Ross, W.A., A.M. Saunders, and R. Marshall. 2006. Common Sense in Environmental Impact Assessment: It Is Not as Common as It Should Be. Impact Assessment and Project Appraisal, volume 24 nomor 1.

Sabaruddin, A. K. 2007. Amdal dan Kewenangan Bapedalda Dalam Menjaga Pelestarian Fungsi Lingkungan Hidup di Kota Balikpapan. Risalah Hukum Fakultas Hukum Unmul. 3 (1):13-20.

Sarbi, S. 2006. Strategi Pengembangan Kapasitas Pengelolaan Lingkungan Hidup di Era Otonomi Daerah Kabupaten Polmas Sulawesi Barat. Jurnal Bumi Lestari, Volume 6 No. 2. 
Sari, Tri Fitri Puspita, Mochamad Makmur \& Mochamad Rozikin. 2014. Efektivitas Implementasi UKL-UPL dalam Mengurangi Kerusakan Lingkungan (Studi pada Badan Lingkungan Hidup Kabupaten Malang dan Masyarakat Sekitar PT Tri Surya Plastik Kecamatan Lawang). Jurnal Administrasi Publik (JAP). 2 (1):161-168.
Wahyono, Suntoro \& Sutarno. 2012. Efektivitas Pelaksanaan Dokumen Lingkungan Dalam Perlindungan dan Pengelolaan Lingkungan Hidup Di Kabupaten Pacitan Tahun 2012. Jurnal EKOSAINS. 4 (2): 43-52. 